\title{
miRNA-10b sponge: An anti-breast cancer study in vitro
}

\author{
AI-LING LIANG ${ }^{1 *}$, TING-TING ZHANG ${ }^{2 *}$, NING ZHOU ${ }^{1}$, CUI YUN WU ${ }^{1}$, MAN-HUA LIN ${ }^{3}$ and YONG-JUN LIU ${ }^{1}$ \\ ${ }^{1}$ Medical Molecular Diagnostics Key Laboratory of Guangdong, and Departments of Biochemistry and \\ Molecular Biology and Clinical Biochemistry, Guangdong Medical University, Dongguan, Guangdong 523808; \\ ${ }^{2}$ Department of Clinical Laboratory, Huangshi City Central Hospital, Huangshi, Hubei 415000; \\ ${ }^{3}$ Department of Clinical Hematology Testing, Guangdong Medical University, Dongguan, Guangdong 523808, P.R. China
}

Received November 5, 2015; Accepted January 7, 2016

DOI: $10.3892 /$ or.2016.4596

\begin{abstract}
Breast cancer is a malignant tumor with the highest incidence among women. Breast cancer metastasis is the major cause of treatment failure and mortality among such patients. MicroRNAs (miRNAs) are a class of small molecular noncoding regulatory RNAs, which act as oncogenes or tumor suppressors in breast cancer. miRNA-10b has been found to exhibit a high expression level in advanced and metastatic breast cancer, and is closely related to breast cancer metastasis. An miRNA sponge is an mRNA with several repeated sequences of complete or incomplete complementarity to the natural miRNA in its $3^{\prime}$ non-translating region. It acts as a sponge adsorbing miRNAs and ensures their separation from their targets and inhibits their function. The present study designed a sponge plasmid against miRNA-10b and transiently transfected it into high and low metastatic human breast cancer cell lines MDA-MB-231 and MCF-7, and analyzed the effects of the miRNA-10b sponge on the growth and proliferation, migration and invasion in these cell lines. qRT-PCR results found that the sponge plasmid effectively inhibited the expression of miRNA-10b, and upregulated the expression of the miRNA-10b target protein HOXD-10. The results from the CCK-8 assay found that the miRNA-10b sponge inhibited the growth of breast cancer cell lines MDA-MB-231 and MCF-7. Results of the plate cloning experiments indicated that the miRNA-10b sponge suppressed the colony formation of the MDA-MB-231 and MCF-7 cells. The results of wound healing and Transwell assays showed that the miRNA-10b sponge inhibited the migration and invasion of the breast cancer cell lines MDA-MB-231 and MCF-7. Our results demonstrated
\end{abstract}

Correspondence to: Professor Yong-Jun Liu, Medical Molecular Diagnostics Key Laboratory of Guangdong, and Departments of Biochemistry and Molecular Biology and Clinical Biochemistry, Guangdong Medical University, Dongguan, Guangdong 523808, P.R. China

E-mail: liuyongjun@gdmc.edu.cn

*Contributed equally

Key words: breast cancer, miRNA-10b, HOXD-10, miRNA sponge, metastasis that the miRNA-10b sponge effectively inhibited the growth and proliferation of breast cancer MDA-MB-231 and MCF-7 cells. In addition, it also restrained the migration and invasion of human highly metastatic breast cancer MDA-MB-231 cells.

\section{Introduction}

Breast cancer has the highest incidence among all female malignant tumors. The incidence of breast cancer has an increasing trend in China (1). The etiology of breast cancer is associated with family genetic factors, estrogen levels, gene mutations and lifestyle (2). Metastasis is a major cause of treatment failure and ultimate death from breast cancer. The exactly mechanism of breast cancer metastasis remains unclear.

MicroRNAs (miRNAs) are a class of small molecular non-coding regulatory RNAs which act as oncogenes or tumor suppressors in breast cancer. Biagioni et al (3) and Iorio et al (4) found that miRNA-10b displayed a high expression level in advanced breast cancer, and may be used as a characteristic molecular marker in early breast cancer metastasis. The miRNA-10b gene is located at the homeobox D10 (HOXD10) gene cluster on chromosome 2 q31.1 and is located in the interval between HOXD-4 and HOXD-8 (3). Ohuchida et al suggested that the main target gene of miRNA-10b, HOXD10, could inhibit metastasis in a variety of solid tumors. In breast cancer, miRNA-10b is highly expressed in metastatic breast cancer and is also strongly associated with distant metastasis (5). Compared with healthy volunteers or lymph node metastasis-negative (N0) breast mammary carcinoma patients, the miRNA-10b level was found to be significantly increased in the blood circulation of patients with lymph node metastatic mammary ductal carcinoma. This suggests that miRNA-10b may serve as a marker to detect lymph node metastasis in breast cancer patients (6). Ma et al found that miRNA-155, miRNA-9a and miRNA-10b were highly expressed in breast cancer cell lines, while only miRNA-10b had specific high expression in metastatic breast cancer cell lines. Moreover, ectopic expression of miR-10b conferred invasiveness to the non-invasive breast cancer cell line SUM149 and also induced metastasis in the invasive but non-metastatic breast cancer cell line SUM159. These results revealed that miRNA-10b acts as a potent pro-metastatic agent (7). Ma et al confirmed that chemically modified nucleotides may silence the expression of miRNA-10b to increase the expression of its target gene 
HOXD-10 and inhibit the distant metastasis of breast cancer in nude mice (8). Taken together, miRNA-10b displays superior application prospect for use as a molecular target for breast cancer treatment.

The miRNA sponge technology was invented by Ebert et al in 2007 (9), whereby long-term miRNA activity can be inhibited. The miRNA sponge is the mRNA that contains several repeated sequences of complete or incomplete complementarity to the natural miRNA 3' non-translating regions. It can act as a sponge adsorbing miRNAs and separating them from their targets. Due to the binding to the specific 'seed' sequences of miRNAs, the sponge can block an entire family of miRNAs with a common 'seed' sequence $(7,10,11)$. The sponge 3' non-translating region contains a number of miRNA target anchor points, which have some mismatch on cutting sites in the RNA-induced silencing complex (RISC). Thus, the sponge mRNA can combine with RISC tightly and not be degraded $(12,13)$. The natural target mRNAs can relieve the inhibition of miRNAs. The miRNA sponge is constructed on a plasmid or virus expression vector with CMV or U6 strong promoter and 2-8 miRNA targeting complementary sequences were inserted at the cloning sites. The recombinant vector is transfected into cells or injected into animals to express the miRNA sponge $(6,10)$. Stable miRNA sponge-expressing cell lines or animal strains can be obtained by screening. Using the technique of miRNA sponge, it was confirmed that the miRNA-15/16 family functions as a tumor-suppressor gene (10).

miRNA-10b is closely associated with metastatic breast cancer, however, to the best of our knowledge no study has reported the biologic activity of the entire miRNA-10b family on the inhibition of the proliferation and metastasis of breast cancer. In the present study, we constructed the miRNA$10 \mathrm{~b}$ sponge and transfected it into breast cancer cell lines MDA-MB-231 and MCF-7. Its effects on the proliferation and metastasis of the breast cancer cells were observed. Our results may provide further clues of breast cancer metastasis.

\section{Materials and methods}

Sponge design and construction of the recombinant plasmid. The miRNA-10b sponge was designed according to a previous design principle $(7,11)$, and the hsa-miRNA-10b-5P sequence was provided by miRNABase database (http://www.mirbase. org), and was synthesized by Shanghai Integrated Biotech Solutions Co., Ltd. The mature hsa-miRNA-10b-5P sequence was: 5'-UACCCUGUAGAACCGAAUUUGUG-3'.

The 'bulge' combination sequence for mature miRNA-10b sequence was:

$$
\begin{gathered}
\text { A } \\
3^{\prime}-\text { G U G U U U A A G } \\
5^{\prime}-\text { C A C A A A U U C A G A A G G G T A-3' sponge }
\end{gathered}
$$

The sequence of the whole miRNA-10b sponge with eight repeat sequences was: 5'-GAATTCCACAAATTCGGAGAA CAGGGTACACAAATTCGGAGAACAGGGTACACAAAT TCGGAGAACAGGGTACACAAATTCGGAGAACAGGGT ACACAAATTCGGAGAACAGGGTACACAAATTCGGAG AACAGGGTACACAAATTCGGAGAACAGGGTACACA
AATTCGGAGAACAGGGTAGGATCCGCCC-3'. Overexpression of the hsa-miRNA-10b-5P target sequence was: 5'-TACCCTGTAGAACCGAATTTGTG-3'.

Hsa-miRNA-10b-5P sponge eukaryotic expression vector and eukaryotic expression vector of hsa-miRNA-10b-5P were constructed by Shanghai Integrated Biotech Solutions Co., Ltd., and the two vectors were carried with eGFP.

Cell groups. Human breast cancer cell lines MDA-MB-231 and MCF-7 were divided into four groups: control (MOCK), miRNA-10b sponge (miRNA-10b sponge), miRNA-10b mimic transfection (miRNA-10b) and miRNA-10b empty plasmid of the transfection group (miRNA-10b NC).

Cell culture. Human breast cancer cell lines MDA-MB-231 and MCF-7 were cultured in Dulbecco's modified Eagle's medium (DMEM) with $10 \%$ fetal bovine serum (FBS), $100 \mathrm{U} / \mathrm{ml}$ penicillin, and $100 \mu \mathrm{g} / \mathrm{ml}$ streptomycin and maintained at $37^{\circ} \mathrm{C}$ in $5 \% \mathrm{CO}_{2}$.

Detection of RNA levels of miRNA-10b and HOXD-10. After the breast cancer MDA-MB-231 and MCF-7 cells were transiently transfected with miRNA-10b and the miRNA-10b sponge for $48 \mathrm{~h}$ using Lipofectamine 2000 liposome (cat. no. 11668-019; Invitrogen, New York, NY, USA), the mRNA levels were detected with qRT-PCR.

miRNA-10b and U6 primers were purchased from Guangzhou RiboBio Co. (Guangzhou, China). Hoxd-10 and GAPDH primers were designed and synthesized by Sangon Bioengineering (Shanghai) Co., Ltd.

The sequence of the primers were: Hoxd-10 (forward primer, 5'-CTGTCATGCTCCAGCTCAACCC-3' and reverse primer, 5'-CTAAGAAAACGTGAGGTTGGCGGTC-3'); GAPDH (forward primer, 5'-TGACTTCAACAGCGACAC CCA-3' and reverse primer, 5'-CACCCTGTTGCTGTAGCC AAA-3').

The reverse transcription reaction system of miRNA-10b consisted of: RNA template $1 \mu \mathrm{g}$, Bulge-Loop ${ }^{\mathrm{TM}}$ miRNA qRT-PCR Starter kit (cat. no. MQP-0102; RiboBio) $(5 \mu \mathrm{M})$ $1 \mu \mathrm{l}, 2.5 \mathrm{X}$ reverse transcription mix $4 \mu \mathrm{l}$, RNase-free $\mathrm{H}_{2} \mathrm{O}$ up to $10 \mu \mathrm{l}$. The reaction conditions consisted of: $42^{\circ} \mathrm{C}$ for $60 \mathrm{~min} \rightarrow 70^{\circ} \mathrm{C}$ for $10 \mathrm{~min} \rightarrow 4^{\circ} \mathrm{C} \infty$. The real-time quantitative PCR reaction system of miRNA-10a and $-10 \mathrm{~b}$ consisted of: $2 \mathrm{X}$ SYBR-Green Mix $10 \mu \mathrm{l}$, reverse transcription product $2 \mu \mathrm{l}$, miRNA forward primer $(10 \mu \mathrm{M}) 0.8 \mu \mathrm{l}$, miRNA reverse primer (10 $\mu \mathrm{M}) 0.8 \mu \mathrm{l}$, Super Pure $\mathrm{H}_{2} \mathrm{O}$ up to $20 \mu \mathrm{l}$; the reaction conditions consisted of: $95^{\circ} \mathrm{C}$ for $10 \mathrm{~min} \rightarrow\left(95^{\circ} \mathrm{C}\right.$ for $2 \mathrm{sec} \rightarrow 58^{\circ} \mathrm{C}$ for $30 \mathrm{sec})$ x 40 cycles $\rightarrow 37^{\circ} \mathrm{C}$ for $30 \mathrm{sec}$.

The reverse transcription reaction system of Hoxd-10 consisted of: 5X PrimeScript RT Master Mix (cat. no. DRR037A; Takara, Japan) $2 \mu \mathrm{l}$, total RNA $1 \mu \mathrm{g}$, RNasefree $\mathrm{dH}_{2} \mathrm{O}$ up to $10 \mu \mathrm{l}$. The reaction conditions consisted of: $37^{\circ} \mathrm{C}$ for $15 \mathrm{~min} \rightarrow 85^{\circ} \mathrm{C}$ for $5 \mathrm{sec} \rightarrow 4^{\circ} \mathrm{C} \infty$. The real-time quantitative PCR reaction system of Hoxd-10 consisted of: 2X FastStart Universal SYBR $10.0 \mu \mathrm{l}$, Green Master ROX (cat. no. 04913850001; Roche, USA) $0.1 \mu \mathrm{l}$, forward primer $(12.5 \mu \mathrm{M}) 0.8 \mu \mathrm{l}$, reverse primer $(12.5 \mu \mathrm{M}) 0.8 \mu \mathrm{l}$, cDNA template $1.0 \mu \mathrm{l}$, Super Pure $\mathrm{H}_{2} \mathrm{O}$ up to $20 \mu \mathrm{l}$. The reaction conditions consisted of: $95^{\circ} \mathrm{C}$ for $30 \mathrm{sec} \rightarrow\left(95^{\circ} \mathrm{C}\right.$ for $5 \mathrm{sec} \rightarrow 60^{\circ} \mathrm{C}$ for $34 \mathrm{sec})$ x 40 cycles $\rightarrow 37^{\circ} \mathrm{C}$ for $30 \mathrm{sec}$. 
Each well in these experiments had three repeated wells and every experiment was repeated three times. The $2^{-\Delta \Delta C q}$ analysis method was used to analyze the experimental results. The expression of the control group was set to one, and the other groups were compared with the control group, and the relative expression level of each group was obtained.

Detection of protein levels of HOXD-10. After breast cancer cell lines MDA-MB-231 and MCF-7 were transiently transfected with miRNA-10b and the miRNA-10b sponge for $72 \mathrm{~h}$ using Lipofectamine 2000 liposome, the total protein extraction and protein concentrations were determined using the RIPA kit (cat. no. C1053) and the BCA protein assay kit (cat. no. P1510) (both from Applygen Technologies Inc., Peking, China). The total protein was electrophoresed with $12 \%$ SDS-PAGE at a constant $120 \mathrm{~V}$ to the bromophenol blue to gel bottom. In addition, semi-dry transfer film at $15 \mathrm{~V}$ was used for $3 \mathrm{~h}$.

Immunoblotting. According to a conventional method (14), the anti HOXD-10 antibody (cat. no. sc-166235; Santa Cruz) was diluted at 1:500 and the secondary antibody (cat. no. C2225) was diluted at 1:2,000 and labeled with horseradish peroxidase. Detection was carried out using SuperSignal ECL Plus (cat. no. P1010) (both from Applygen Technologies Inc.), and images were captured using X-ray film. The expression of HOXD-10/ $\beta$-actin protein was analyzed by BandScan5.0.

Analysis of cell growth with the CCK-8 assay. After breast cancer cell lines MDA-MB-231 and MCF-7 were transiently transfected with miRNA-10b and the miRNA-10b sponge for 24, 48 and $72 \mathrm{~h}$ using Lipofectamine 2000 liposome, the CCK-8 kit (cat. no. CK04-13; Dojindo, Japan) was used to detect cell growth ability (15); each group had three repeat wells and the experiment was repeated three times.

$$
\begin{aligned}
\text { Survival rate }(\%)= & A_{\text {experimental group }}-A_{\text {blank group }} / A_{\text {control group }}- \\
& A_{\text {blank group }} \times 100
\end{aligned}
$$

Inhibition rate $(\%)=1$ - survival rate

Effects of the colony formation of MDA-MB-231 and MCF-7 cells. After breast cancer cell lines MDA-MB-231 and MCF-7 were transiently transfected with miRNA-10b and the miRNA-10b sponge for $24 \mathrm{~h}$ using Lipofectamine 2000 liposome, the proliferation ability of the breast cancer cells was analyzed with flat plate cloning experiments $(16,17)$. The cells were adjusted to $1,000 / \mathrm{ml}$ and seeded on a 6-well culture plate and the culturing was continued for 10 days until the clones could be observed using the naked eye ( $>60$ cells/clone). The cells were then fixed with methanol for 20 min washed with PBS twice. Finally the results were recorded with ChemiDoc XRS imaging system. Each group had three repeat wells and this experiment was repeated three times. Clone formation rate $=($ clones number/inoculated cell number $) \times 100 \%$.

Assessment of MDA-MB-231 and MCF-7 cell invasion. After breast cancer cell lines MDA-MB-231 and MCF-7 were transiently transfected with miRNA-10b and the miRNA-10b sponge for $48 \mathrm{~h}$ using Lipofectamine 2000 liposome, the invasive ability of the cells was evaluated with a Transwell assay. The specific operation was carried out according to the standard procedure $(18,19)$. Crystal violet staining was observed using an optical microscope (magnification, x100), and the diameter was randomly selected from four visual field. The average value of each field was calculated.

Assessment of the migratory ability of the MDA-MB-231 and MCF-7 cells. After breast cancer cell lines MDA-MB-231 and MCF-7 were transiently transfected with miRNA-10b and the miRNA-10b sponge for $48 \mathrm{~h}$ using Lipofectamine 2000 liposome, the migratory ability of the cells was evaluated with a wound healing assay. Specific operations were carried out as previously described in the literature $(20,21)$. Analysis of cell migration was carried out by ImageJ software. In this experiment, each well had three repeat wells and this experiment was repeated three times.

Statistical analysis. The experimental results were analyzed using SPSS 17.0. The data of the groups were compared with the standard deviation (mean \pm SD). The average number of the two groups was compared with t-test. The average number of multiple groups were analyzed by ANOVA, and the test level was 0.05 .

\section{Results}

Reduction in miRNA-10b expression increases HOXD-10 $m R N A$ expression. The expression of miRNA-10b was analyzed by real-time quantitative RT-PCR in the human highly metastatic breast cancer cell line MDA-MB-231 and the human low metastatic breast cancer cell line MCF-7. The results showed that the expression of miRNA-10b in the MDA-MB-231 cells was 2.23-fold that of the MCF-7 cells $(\mathrm{P}<0.05)$, which indicated that the expression level of miRNA-10b in the highly metastatic breast cancer MDA-MB-231 cells was relatively high (Fig. 1A).

The miRNA-10b mimics and the miRNA-10b sponge were transfected into the human highly metastatic breast cancer cell line MDA-MB-231 and the low metastatic breast cancer cell line MCF-7. The expression level of miRNA-10b was detected by real-time qRT-PCR. It increased to 7.07fold $(\mathrm{P}<0.05)$ and 16.9 -fold $(\mathrm{P}<0.05)$ or decreased to $50.0 \%$ $(\mathrm{P}<0.05)$ and $3.00 \%(\mathrm{P}<0.05)$ compared with the miRNA-10 $\mathrm{NC}$ group in the human highly metastatic breast cancer cell line MDA-MB-231 and the low metastatic breast cancer cell line MCF-7 (Fig. 1B and C). These results demonstrated that the miRNA-10b mimics and the miRNA-10b sponge could successfully upregulate or downregulate the miRNA-10b expression level in these two cell lines.

The real-time qRT-PCR results showed that the mRNA expression level of HOXD-10 in the human highly metastatic breast cancer cell line MDA-MB-231 was $31.0 \%$ of that noted in the low metastatic breast cancer MCF-7 cells $(\mathrm{P}<0.05)$, which indicated that the mRNA expression level of HOXD-10 was relatively high in the low metastatic human breast cancer cell line MCF-7 (Fig. 2A).

The miRNA-10b mimics and the miRNA-10b sponge were transfected into the MDA-MB-231 and MCF-7 cell lines. The mRNA expression level of HOXD-10 was detected by real- 
A

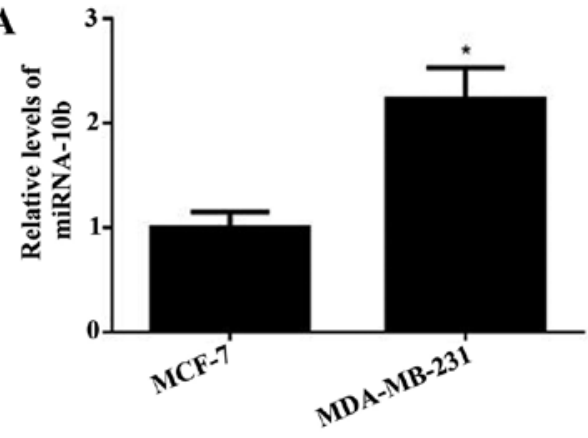

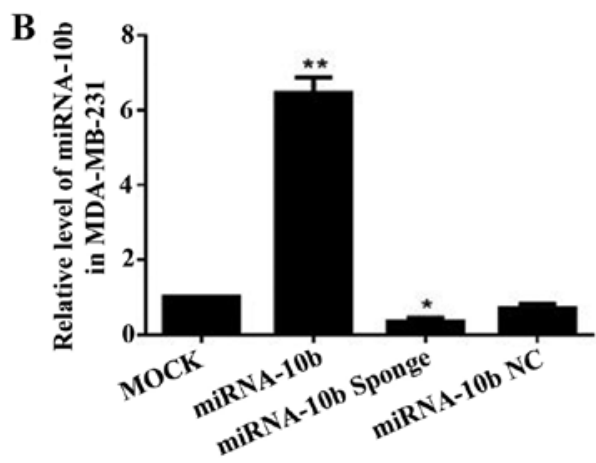

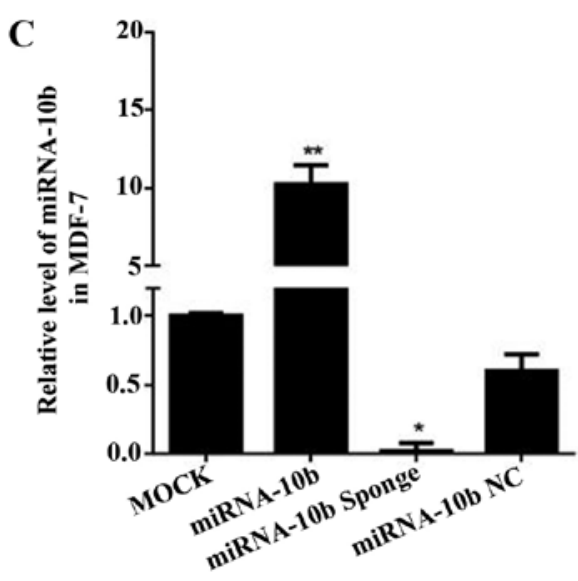

Figure 1. Expression of miRNA-10b after transient transfection with miRNA-10b and the miRNA-10b sponge in MDA-MB-231 and MCF-7 cells. (A) The expression of miRNA-10b in the MDA-MB-231 and MCF-7 cells, ${ }^{*} \mathrm{P}<0.05$ vs. MCF-7. (B) The expression of miRNA-10b after transient transfection with miRNA-10b and the miRNA-10b sponge in the MDA-MB-231 cells, ${ }^{*} \mathrm{P}<0.05$ vs. miRNA-10b NC; ${ }^{* *} \mathrm{P}<0.01$ vs. MOCK. (C) The expression of miRNA-10b after transient transfection with miRNA-10b and the miRNA-10b sponge in the MCF-7 cells, ${ }^{*} \mathrm{P}<0.05$ vs. miRNA-10b NC; ${ }^{* *} \mathrm{P}<0.01 \mathrm{vs}$. miRNA-10b NC.

time qRT-PCR. Expression of HOXD-10 was decreased to $4.65 \%(\mathrm{P}<0.05)$ and $16.9 \%(\mathrm{P}<0.05)$ or increased to 16.9 -fold $(\mathrm{P}<0.01)$ and 1.53-fold $(\mathrm{P}>0.05)$ compared with the miRNA$10 \mathrm{~b}$ NC group in the MDA-MB-231 and MCF-7 cell lines, respectively (Fig. $2 \mathrm{~B}$ and $\mathrm{C}$ ). These results demonstrated that the miRNA-10b mimics and the miRNA-10b sponge could downregulate or upregulate the HOXD-10 expression level in these two cell lines.

Transient transfection of the miRNA-10b sponge upregulates the protein expression level of HOXD-10 in the MDA-MB-231 cells. The HOXD-10 protein expression levels in the human highly metastatic breast cancer cell line MDA-MB-231 and the human low metastatic breast cancer cell line MCF-7 are shown in Fig. 2D-1. The gray scale scanning results indicated that the relative protein expression of HOXD-10 in the MCF-7 cells was 1.47-fold of that noted in the MDA-MB-231 cells with the difference being significant ( $\mathrm{P}<0.05$; Fig. 2D-2).

The miRNA-10b mimics and the miRNA-10b sponge were transfected into the MDA-MB-231 and MCF-7 cell lines. The protein expression level of HOXD-10 was detected by western blotting. The protein expression level of HOXD-10 was decreased to $51.3 \%(\mathrm{P}<0.05)$ and $20.2 \%(\mathrm{P}<0.05)$ or increased to 1.3 -fold $(\mathrm{P}<0.05)$ and was $89.1 \%(\mathrm{P}>0.05)$ compared with the miRNA-10b NC group in the MDA-MB-231 and MCF-7 cell lines, respectively (Fig. 2E and F). These results demonstrated that the miRNA-10b mimics and the miRNA-10b sponge could affect the HOXD-10 protein expression level in these two cell lines.
Transient transfection of the miRNA-10b mimic and the miRNA-10b sponge affects the proliferation of the $M D A-M B-231$ cells. The survival rate of the breast cancer cell line MDA-MB-231 was detected using the CCK-8 kit after transient transfection with miRNA-10b, the miRNA-10b sponge and miRNA-10b NC. The cell survival rate at three time points of 24,48 and $72 \mathrm{~h}$ were determined, respectively. At 24 and $48 \mathrm{~h}$, the three transient transfection groups exhibited no change in growth, and there was no significant difference compared with their control groups $(\mathrm{P}>0.05)$. However, at $72 \mathrm{~h}$, the survival rate of the miRNA-10b group was 1.20 -fold of that noted in its control group $(\mathrm{P}<0.05)$ and the miRNA-10b sponge group was $78.8 \%$ of that noted in its control group $(\mathrm{P}<0.05)$. miRNA-10b NC did not affect the survival rate of the cell line $(\mathrm{P}>0.05)$. The results suggest that miRNA-10b increased the growth of the MDA-MB-231 cells, and the miRNA-10b sponge inhibited the growth of this cell line at $72 \mathrm{~h}$ (Table I and Fig. 3A). However, the three transfection treatments did not affect the proliferation of the MCF-7 cell line ( $\mathrm{P}>0.05$; Table I and Fig. 3B).

Transient transfection with the miRNA-10b mimics and the miRNA-10b sponge affects the colony formation of the MDA-MB-231 cells. After transient transfection with miRNA-10b, the miRNA-10b sponge and miRNA-10b NC, the proliferation of human breast cancer cell line MDA-MB231 was evaluated by a plate clone formation assay. The clone formation rate in the miRNA-10b sponge group was $42.8 \%$ of that noted in the miRNA-10b NC group $(\mathrm{P}<0.05)$ and in 

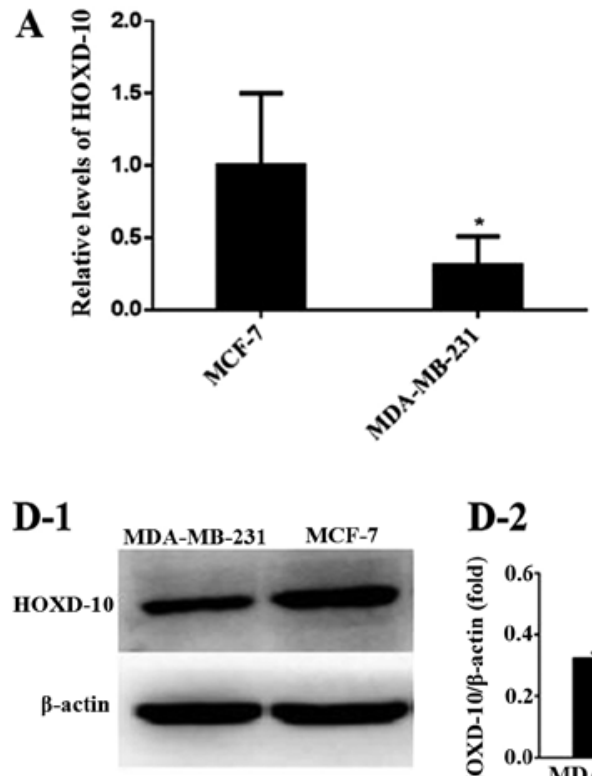

D-2
B
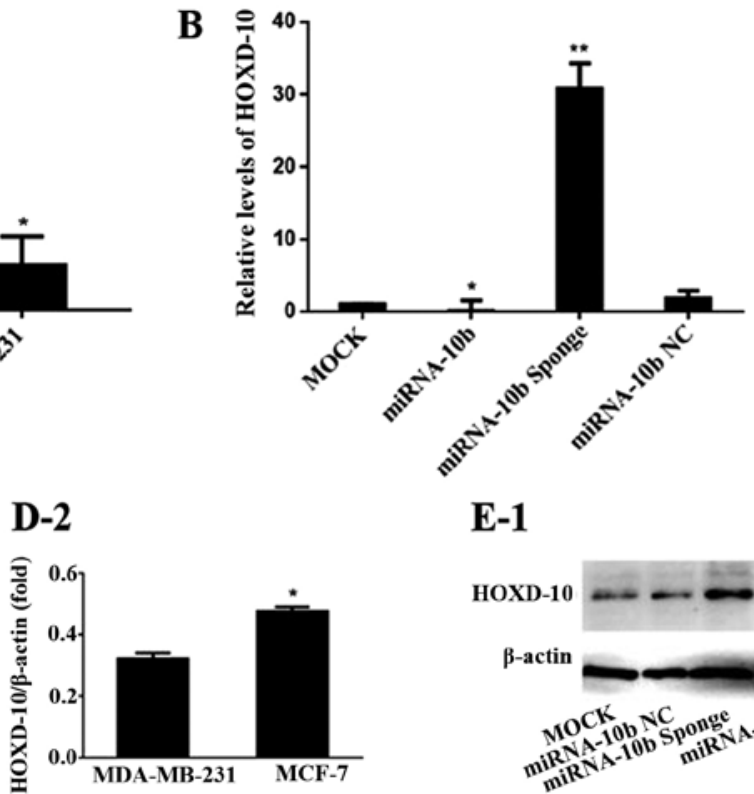

F-1

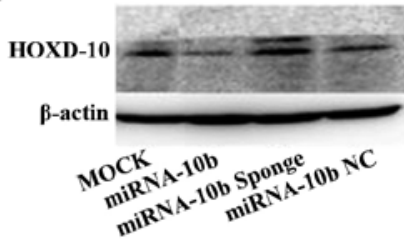

E-1

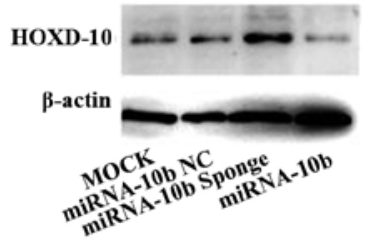

E-2

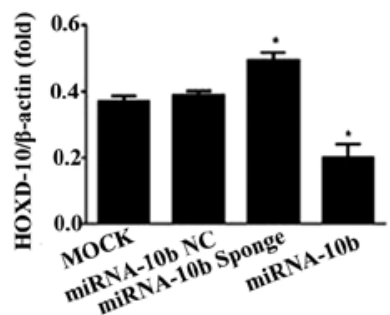

F-2

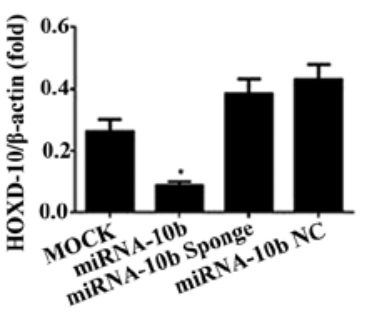

Figure 2. mRNA and protein expression levels of HOX-10 in the MDA-MB-231 and MCF-7 cells. (A) The mRNA expression of HOXD-10 mRNA in the MDA-MB-231 and MCF-7 cells, "P<0.05 vs. MCF-7. (B) The mRNA expression of HOXD-10 after transient transfection with miRNA-10b and the miRNA10b sponge in the MDA-MB-231 cells, ${ }^{*} \mathrm{P}<0.05$ vs. miRNA-10b NC; ${ }^{* *} \mathrm{P}<0.01$ vs. miRNA-10b NC. (C) The mRNA expression of HOXD-10 after transient transfection with miRNA-10b and the miRNA-10b sponge in the MCF-7 cells, ${ }^{*} \mathrm{P}<0.05$ vs. miRNA-10b NC. (D) The protein expression of HOXD-10 in the MDA-MB-231 and MCF-7 cells: (D-1) HOXD-10 protein electrophoresis map; (D-2) histogram of the gray values of the relative HOXD-10 protein expression levels, ${ }^{*} \mathrm{P}<0.05$ vs. MDA-MB-231. (E) The protein expression of HOXD-10 after transient transfection with miRNA-10b and the miRNA-10b sponge in the MDA-MB-231 cells: (E-1) HOXD-10 protein electrophoresis map; (E-2) histogram of the gray values of the relative HOXD-10 protein expression levels, ${ }^{*} \mathrm{P}<0.05$ vs. miRNA-10b NC. (F) The protein expression of HOXD-10 after transient transfection with miRNA-10b and the miRNA-10b sponge in the MCF-7 cells: (F-1) HOXD-10 protein electrophoresis map; (F-2) histogram of the gray values of the relative HOXD-10 protein expression levels, "P $<0.05$ vs. miRNA-10b NC.

the miRNA-10b group the rate was 1.50 -fold of that noted in the miRNA-10b NC group $(\mathrm{P}<0.05)$. These results indicated that miRNA-10b and the miRNA-10b sponge had an effect on the proliferation of MDA-MB-231 cells (Table II and Fig. 3C). The results in MCF-7 cells showed that the miRNA-10b mimic and the miRNA-10b sponge did not affect the clone formation of the MCF-7 cells (P>0.05; Table II and Fig. 3D).

Transient transfection with the miRNA-10b sponge inhibits the invasive ability of the human highly metastatic breast cancer cell line $M D A-M B-231$. The effect on the invasive ability of the MDA-MB-231 cells was evaluated with a Transwell assay after transient transfection with miRNA-10b, the miRNA-10b sponge and miRNA-10b NC. After transient transfection for $48 \mathrm{~h}$, the cell number that invaded through the Matrigel in the miRNA-10b sponge group was $61.2 \%$ of that noted in the miRNA-10b NC group $(\mathrm{P}<0.05)$. The cell number that invaded through the Matrigel in the miRNA-10b transfection group was 1.84-fold of that noted in the miRNA-10b NC group $(\mathrm{P}<0.05$,
Fig. 4A and B). These results indicated that the miRNA-10b sponge inhibited the invasive ability of the MDA-MB-231 cells and that miRNA-10b could facilitate the invasion of the MDA-MB-231 cells. The same experiment was performed in the MCF-7 cells. The results showed that the miRNA-10b mimic and the miRNA-10b sponge had no effect on the invasive ability of the MCF-7 cells ( $\mathrm{P}>0.05$, data not shown).

Transient transfection with the miRNA-10b sponge and miRNA-10b affects the migratory ability of the human breast cancer cell lines. A wound healing assay was used to evaluate the effect miRNA-10b and the miRNA-10b sponge on the migratory ability of the human breast cancer cell line MDA-MB-231. At $24 \mathrm{~h}$ after transient transfection with miRNA-10b, the healing percentage was 1.30 -fold compared to the value of the miRNA-10b NC group $(\mathrm{P}<0.05)$; at $48 \mathrm{~h}$ its healing percentage was 1.26 -fold compared to the value of the miRNA-10b NC group $(\mathrm{P}<0.05)$. At 24 and $48 \mathrm{~h}$ after transient transfection with the miRNA-10b sponge, the healing 

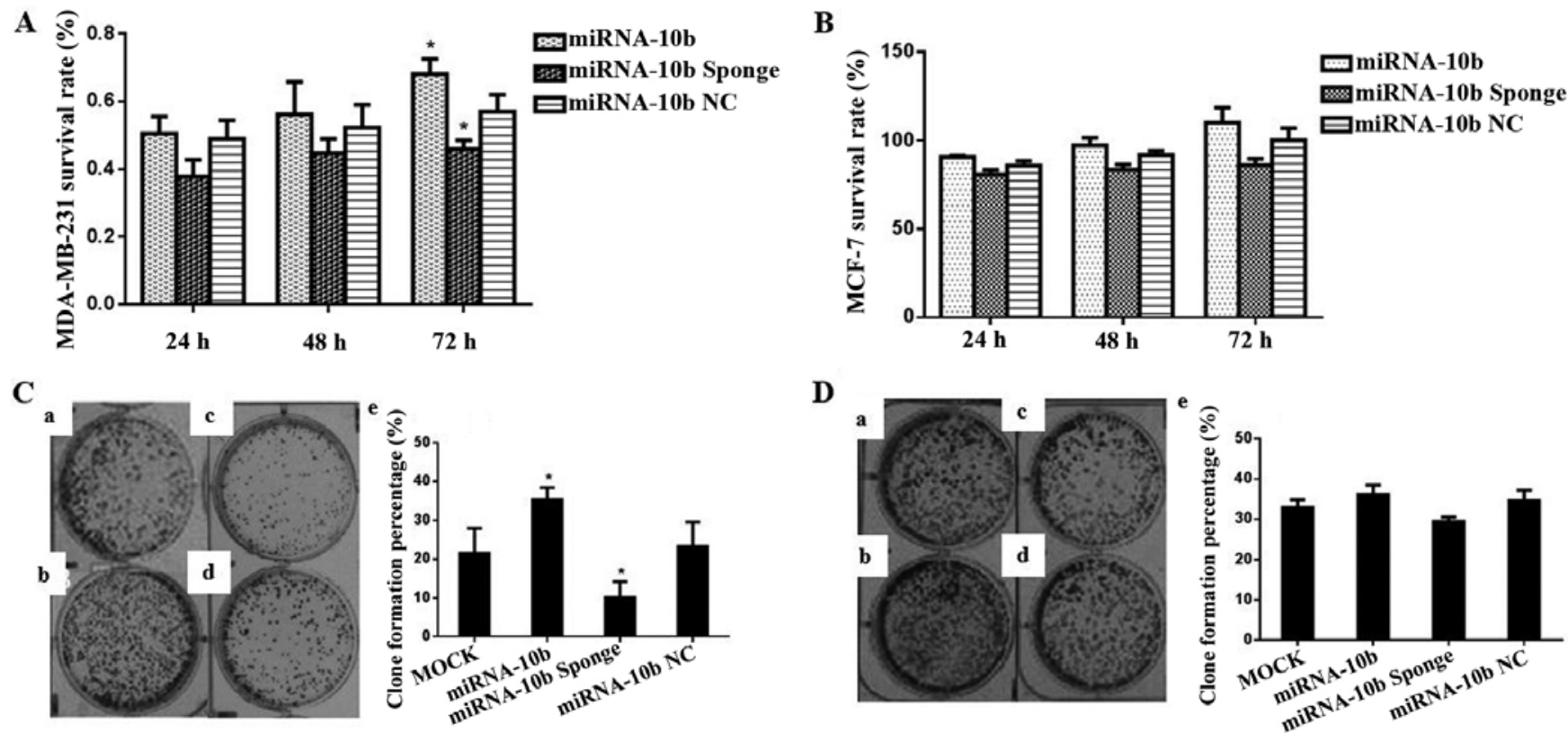

Figure 3. Effect of the transient transfection of miRNA-10b and the miRNA-10b sponge on the proliferation and clone formation of the MDA-MB-231 and MCF-7 cells. (A) Proliferation of the MDA-MB-231 cells after transient transfection with miRNA-10b and the miRNA-10b sponge, ${ }^{*} \mathrm{P}<0.05$ vs. miRNA-10b NC. (B) Proliferation of MCF-7 cells after transient transfection with miRNA-10b and the miRNA-10b sponge. (C) Clone formation of the MDA-MB-231 cells after transient transfection with miRNA-10b and the miRNA-10b sponge: $a$, the clone formation plate of the MOCK group; $b$, the clone formation plate of the miRNA-10b group; $c$, the clone formation plate of the miRNA-10b sponge group; $d$, the clone formation plate of the miRNA-10b NC group; e, histogram showing the clone formation in each group, ${ }^{\mathrm{P}}<0.05 \mathrm{vs}$. miRNA-10b NC. (D) Clone formation of the MCF-7 cells after transient transfection with miRNA-10b and the miRNA-10b sponge; $a$, the clone formation plate of the MOCK group; $b$, the clone formation plate of the miRNA-10b group; $c$, the clone formation plate of the miRNA-10b sponge group; $d$, the clone formation plate of the miRNA-10b NC group; e, histogram showing the clone formation in each group.

Table I. Effect of the transient transfection of miRNA-10b and the miRNA-10b sponge on the survival rate of the MCF-7 and MDA-MB-231 cells (mean \pm SD).

\begin{tabular}{|c|c|c|c|c|c|c|c|c|c|}
\hline \multirow[b]{3}{*}{ Cell line } & \multicolumn{8}{|c|}{ Plasmid } & \\
\hline & \multicolumn{3}{|c|}{ miRNA-10b } & \multicolumn{3}{|c|}{ miRNA-10b sponge } & \multicolumn{3}{|c|}{ miRNA-10b NC } \\
\hline & $24 \mathrm{~h}$ & $48 \mathrm{~h}$ & $72 \mathrm{~h}$ & $24 \mathrm{~h}$ & $48 \mathrm{~h}$ & $72 \mathrm{~h}$ & $24 \mathrm{~h}$ & $48 \mathrm{~h}$ & $72 \mathrm{~h}$ \\
\hline MCF-7 & $0.907 \pm 0.012$ & $0.97 \pm 0.072$ & $1.102 \pm 0.145$ & $0.809 \pm 0.045$ & $0.836 \pm 0.05$ & $0.862 \pm 0.02$ & $0.859 \pm 0.044$ & $0.919 \pm 0.04$ & $1.001 \pm 0.12$ \\
\hline MDA-MB-231 & $0.505 \pm 0.050$ & $0.562 \pm 0.096$ & $0.680 \pm 0.045^{\mathrm{a}}$ & $0.379 \pm 0.065$ & $0.447 \pm 0.042$ & $0.459 \pm 0.026^{\mathrm{a}}$ & $0.489 \pm 0.055$ & $0.523 \pm 0.067$ & $0.570 \pm 0.051$ \\
\hline
\end{tabular}

${ }^{\mathrm{a}} \mathrm{P}<0.05$ vs. miRNA-10b NC.

Table II. Effect of the transient transfection of miRNA-10b and the miRNA-10b sponge on the clone formation of the MCF-7 and MDA-MB-231 cells (mean \pm SD).

\begin{tabular}{lrrrr}
\hline Cell lines & \multicolumn{1}{c}{ MOCK } & miRNA-10b & miRNA-10b sponge & miRNA-10b NC \\
\hline MCF-7 & $32.93 \pm 1.922$ & $36.2 \pm 2.291$ & $29.47 \pm 1.060$ & $34.6 \pm 2.651$ \\
MDA-MB-231 & $21.533 \pm 6.445$ & $35.267 \pm 3.153^{\mathrm{a}}$ & $10.1 \pm 4.133^{\mathrm{a}}$ & $23.333 \pm 6.191$ \\
\hline
\end{tabular}

${ }^{\mathrm{a} P}<0.05$ vs. miRNA-10b NC.

percentage was 87.7 and $67.4 \%$ when compared with the value of the miRNA-10b NC group $(\mathrm{P}<0.05)$. All the above results indicated that the miRNA-10b sponge inhibited the migration of the MDA-MB-231 cells at 24 and $48 \mathrm{~h}$ (Fig. 5A and B).
The same experiment was carried out in the MCF-7 cells. The results showed that the healing percentages were 2.98- and 1.66-fold of the value of the miRNA-10b NC group at 24 and $48 \mathrm{~h}$ after transient transfection with miRNA-10b 
A
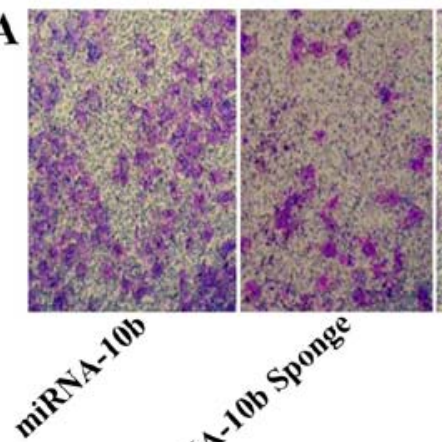
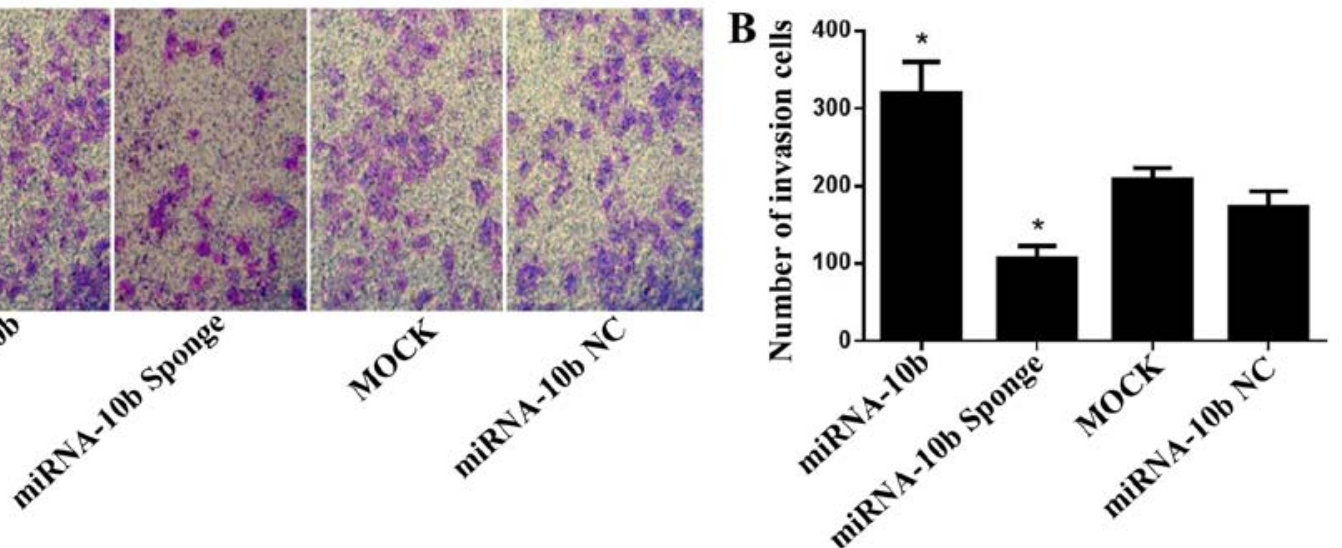

Figure 4. Effect of the transient transfection of miRNA-10b and the miRNA-10b sponge on the invasive capability of the MDA-MB-231 cells (magnification, x100). (A) Images of the cells through Matrigel and stained with crystal violet (magnification, x100) in the Transwell assay in each group. (B) Histrogram showing the number of cells that invaded through the Matrigel, ${ }^{*} \mathrm{P}<0.05$ vs. miRNA-10b.

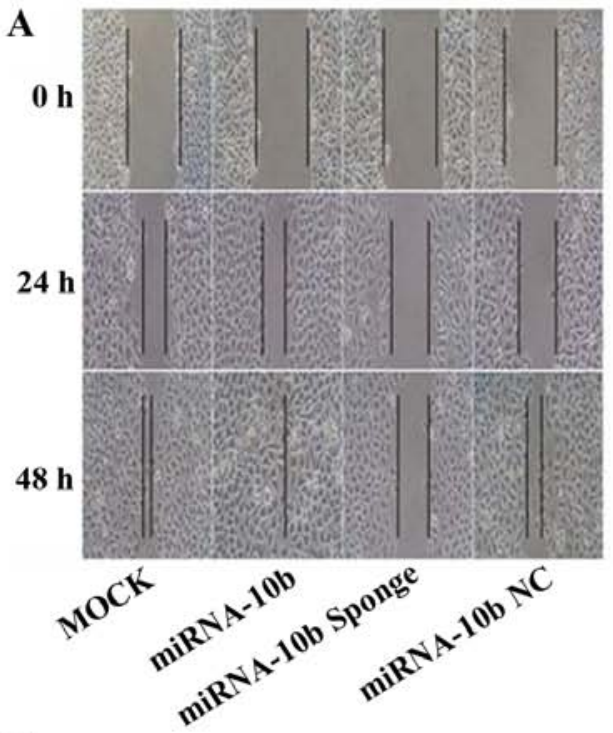

B

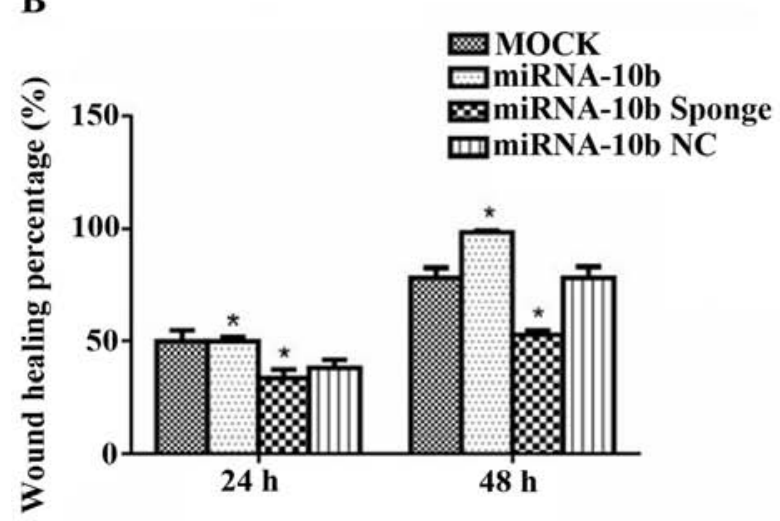

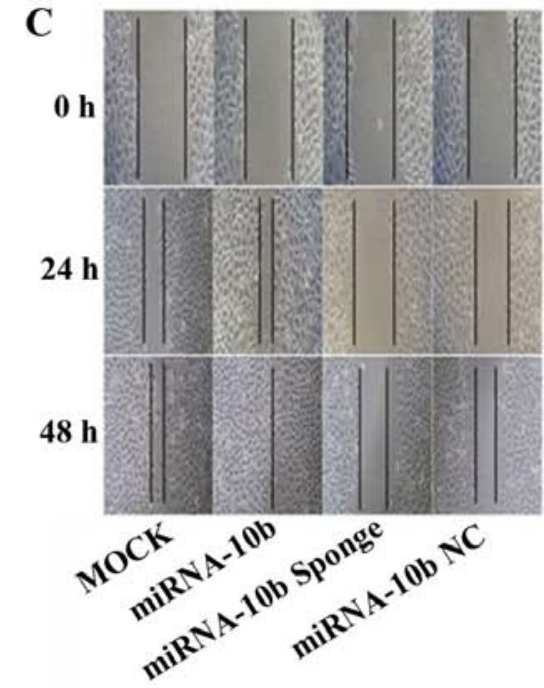

D

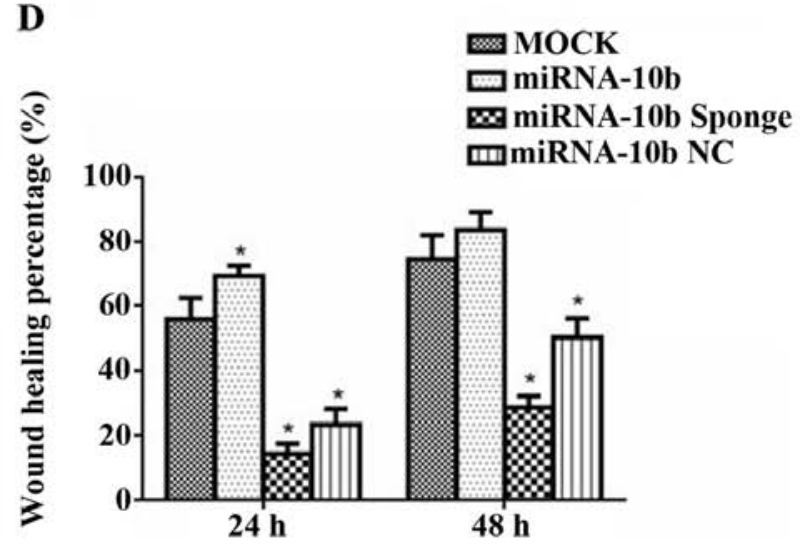

Figure 5. Effect of the transient transfection of miRNA-10b and the miRNA-10b sponge on the migratory capability of the MDA-MB-231 cells (magnification, x100). (A) The MDA-MB-231 cell migration of each group in the wound healing assay at different times (magnification, x100). (B) Histogram showing the MDA-MB-231 cell migration percentage of each group at different times, ${ }^{*} \mathrm{P}<0.05$ vs. miRNA-10b. (C) The MCF-7 cell migration of each group in the wound healing assay at different times (magnification, x100). (D) Histogram showing the MCF-7 cell migration percentage of each group at different times, ${ }^{*} \mathrm{P}<0.05$ vs. miRNA-10b.

$(\mathrm{P}<0.05)$. At 24 and $48 \mathrm{~h}$ after transient transfection with the miRNA-10b sponge, the healing percentages were 61.4 and $56.9 \%$ of the value of the miRNA-10b NC group $(\mathrm{P}<0.05)$.
At $24 \mathrm{~h}$ after transient transfection with miRNA-10b NC, the healing percentage was $41.6 \%$ of that in the MOCK group $(\mathrm{P}<0.05)$; however, there was no significant difference at $48 \mathrm{~h}$ 
( $\mathrm{P}>0.05)$, which indicated that the transient transfection with miRNA-10b NC for $48 \mathrm{~h}$ had no effect on the migration of the MCF-7 cells. These results indicated that the miRNA$10 \mathrm{~b}$ sponge inhibited the migration of the MCF-7 cells after transfection at 24 and $48 \mathrm{~h}$; and miRNA-10b could only improve the migration of the MCF-7 cells after transfection at $48 \mathrm{~h}$ (Fig. 5C and D).

\section{Discussion}

MicroRNAs (miRNAs) are a type of small non-encoding RNAs, which regulate gene expression by binding with target mRNAs. miRNAs usually bind to the $3^{\prime}$ untranslated region (3' UTR) of mRNAs of the target and inhibit the translation of target proteins $(22,23)$. Each miRNA can have multiple target genes, and different miRNAs can also regulate the same target gene. Thus, they produce a complex regulatory network and finely and precisely regulate the expression of function genes (24-26). miRNAs may play an oncogene or tumor-suppressor role in tumorgenesis and development, and can regulate tumor proliferation, invasion, apoptosis and drug resistance $(27,28)$.

In the present study the miRNA-10b sponge was constructed containing multiple repeat sequences complementary with the seed sequence of miRNA-10. Based on the literature $(8,29$ 31) and TargetScan predicting, we selected HOXD-10 as the research target gene of miRNA-10b, which is relate with tumor invasion and metastasis $(25,32)$. miRNA-10b inhibits the transcription of HOXD-10, and consequently, HOXD-10 inhibits the metastasis of breast cancer. Thus, the expression level of miRNA-10b is closely related to the metastasis of breast cancer (7).

The present study clarified that the overexpression of miRNA-10b increased the expression level of miRNA-10b and decreased the mRNA and protein expression levels of HOXD-10; and the miRNA-10b sponge inhibited the expression level of miRNA-10b and promoted the mRNA and protein expression levels of HOXD-10. However, the effect of the miRNA-10b sponge on the MDA-MB-231 cells was more obvious than that noted on the MCF-7 cells, which may be related to the higher background quantity of miRNA-10b in MDA-MB-231 cells. These results showed that our designed miRNA-10b sponge plasmid containing a bulge sequence was a success.

The present study demonstrated that miRNA-10b promoted the proliferation of breast cancer cells and this promotion was more obvious in the MDA-MB-231 cells than that in the MCF-7 cells, which was related with the strong proliferation ability of MCF-7 cells and growth in clustering. In addition, the miRNA-10b sponge inhibited the proliferation and clone formation ability of the MDA-MB-231 cells, which may be beneficial for improving the therapy of tumors with high expression of miRNA-10b. Ibrahim et al (33) verified our results. They found that syndecan-1 is a new target protein of miRNA-10b. Overexpression of miRNA-10b moderately increased the survival rate of MDA-MB-231 cells in syndecan-1-depleted cells. These results indicated that overexpression of miRNA-10b may increase MDA-MB-231 cell proliferation. Our results demonstrated that miRNA-10b may increase the survival rate of MDA-MB-231 cells from two aspects, positive and negative. Whether this effect is associated with other molecules needs further research.

Metastasis is the main cause of breast cancer treatment failure and the majority of these patients succumb to the disease due to tumor recurrence and metastasis. Thus, the study of breast cancer invasion and metastasis is conducive to the clinical treatment of breast cancer to provide an experimental basis. Transwell and wound healing assays demonstrated that miRNA-10b promoted the invasion and migration of breast cancer cells and the miRNA-10b sponge inhibited invasion and migration. Our results showed that miRNA-10b-mediated breast cancer cell invasion and migration was associated with HOXD-10, one of the miRNA-10b target proteins. However, Ibrahim et al (33) showed that the influence of miRNA-10b on breast cancer cell invasion and migration was associated with another target protein, Syndecan-1. Yet, these findings suggested that miRNA-10b is closely related to breast cancer invasion and migration. For this reason, there have been many studies on miRNA-10b. For example, Yigit et al (34) and Jin et al (35) used nanoparticles to suppress miRNA-10b and to prevent the invasion and metastasis of breast cancer. This is a new research hot spot in the field of miRNAs.

miRNA sponge technology was invented nearly 10 years ago, yet there are few studies concerning miRNA sponges in breast cancer. A recent breast cancer study (36) used a sponge plasmid for four miRNAs. The advantage of the miRNA sponge is obvious that it can suppress multiple miRNAs at the same time, producing a variety of effects. However, this may also be a disadvantage. Since an miRNA can regulate multiple target proteins, suppression of multiple miRNAs occurs at the same time. This will affect the expression of more downstream target proteins leading to unexpected side-effects. Therefore, we believed that the treatment of tumors with miRNA sponge technology should be carried out with caution. We should not pursue the aim of inhibiting tumors and at the same time suppresing many miRNAs

These studies indicate that miRNA-10b plays an important role in the invasion and metastasis of breast cancer. Sponge technology is a very effective means of the inhibition of miRNAs. Hence, a sponge for miRNA-10b may be an important treatment for breast cancer.

In conclusion, in the present study, the miRNA-10b sponge was constructed against the seed sequence of miRNA-10b. The results demonstrated that the miRNA-10b sponge inhibited the expression of miRNA-10b, reduced the invasion and migration ability of breast cancer cells, but also inhibited the growth and proliferation of breast cancer cells, which provide the experimental basis for the development of miRNA sponge technology as a target for breast cancer treatment. At the same time, the miRNA sponge is designed for the common 'seed' of an miRNA family. It can be used to inhibit the expression of an miRNA family and it may have a wider application prospect in tumor targeted therapy.

\section{Acknowledgements}

The present study was supported by the National Natural Science Foundation of China (no. 81071853), and the College Research Institutions of Dongguan City Science and Technology Projects (no. 201010815210). 


\section{References}

1. Bertucci F and Birnbaum D: Reasons for breast cancer heterogeneity. J Biol 7: 6, 2008.

2. Boyle P and Levin B (eds): Colorectal cancer. In: World Cancer Report 2008. IARC Press, Lyon, pp374-378, 2008.

3. Biagioni F, Bossel Ben-Moshe N, Fontemaggi G, Yarden Y, Domany E and Blandino G: The locus of microRNA-10b: A critical target for breast cancer insurgence and dissemination. Cell Cycle 12: 2371-2375, 2013.

4. Iorio MV, Ferracin M, Liu CG, Veronese A, Spizzo R, Sabbioni S, Magri E, Pedriali M, Fabbri M, Campiglio M, et al: MicroRNA gene expression deregulation in human breast cancer. Cancer Res 65: 7065-7070, 2005.

5. Ohuchida K, Mizumoto K, Lin C, Yamaguchi H, Ohtsuka T, Sato N, Toma H, Nakamura M, Nagai E, Hashizume M, et al MicroRNA-10a is overexpressed in human pancreatic cancer and involved in its invasiveness partially via suppression of the HOXA1 gene. Ann Surg Oncol 19: 2394-2402, 2012.

6. Chen W, Cai F, Zhang B, Barekati Z and Zhong XY: The level of circulating miRNA-10b and miRNA-373 in detecting lymph node metastasis of breast cancer: Potential biomarkers. Tumour Biol 34: 455-462, 2013.

7. Ma L, Teruya-Feldstein $\mathrm{J}$ and Weinberg RA: Tumour invasion and metastasis initiated by microRNA-10b in breast cancer. Nature 449: 682-688, 2007

8. Ma L, Reinhardt F, Pan E, Soutschek J, Bhat B, Marcusson EG, Teruya-Feldstein J, Bell GW and Weinberg RA: Therapeutic silencing of miR-10b inhibits metastasis in a mouse mammary tumor model. Nat Biotechnol 28: 341-347, 2010.

9. Ebert MS, Neilson JR and Sharp PA: MicroRNA sponges: Competitive inhibitors of small RNAs in mammalian cells. Nat Methods 4: 721-726, 2007.

10. Liu Z, Zhu J, Cao H, Ren H and Fang X: miR-10b promotes cell invasion through RhoC-AKT signaling pathway by targeting HOXD10 in gastric cancer. Int J Oncol 40: 1553-1560, 2012.

11. Zhao K: MicroRNA-10a inhibits the growth of hepatocellular carcinoma cells and discussion of its mechanism. Peking Union Medical College. Peking, pp16-24, 2014.

12. Tay FC, Lim JK, Zhu H, Hin LC and Wang S: Using artificial microRNA sponges to achieve microRNA loss-of-function in cancer cells. Adv Drug Deliv Rev 81: 117-127, 2015.

13. Meister G, Landthaler M, Dorsett $Y$ and Tuschl T: Sequencespecific inhibition of microRNA- and siRNA-induced RNA silencing. RNA 10: 544-550, 2004.

14. Liu Y, Li Y, Wang H, Yu J, Lin H, Xu D, Wang Y, Liang A, Liang $\mathrm{X}$, Zhang $\mathrm{X}$, et al: $\mathrm{BH} 3$-based fusion artificial peptide induces apoptosis and targets human colon cancer. Mol Ther 17: $1509-1516,2009$.

15. Morita Y, Naka T, Kawazoe Y, Fujimoto M, Narazaki M, Nakagawa R, Fukuyama H, Nagata S and Kishimoto T: Signals transducers and activators of transcription (STAT)-induced STAT inhibitor-1 (SSI-1)/suppressor of cytokine signaling-1 (SOCS-1) suppresses tumor necrosis factor alpha-induced cell death in fibroblasts. Proc Natl Acad Sci USA 97: 5405-5410, 2000.

16. Zhu AL, Wang F, Fan QX, He W, Wang LX and Zhao PR: Apoptosis and growth arrest of human esophageal squamous cell carcinoma cell EC9706 induced by Fufangkushen injection. Zhonghua Yi Xue Za Zhi 91: 2797-2800, 2011 (In Chinese).

17. An GZ, Xu H, Zhou Y, Du L, Miao X, Jiang DP, Li KC, Guo GZ, Zhang $\mathrm{C}$ and Ding GR: Effects of long-term $50 \mathrm{~Hz}$ power-line frequency electromagnetic field on cell behavior in Balb/c 3T3 cells. PLoS One 10: e0117672, 2015.

18. Liang AL, Qian HL, Zhang TT, Zhou N, Wang HJ, Men XT, Qi W, Zhang PP, Fu M, Liang X, et al: Bifunctional fused polypeptide inhibits the growth and metastasis of breast cancer. Drug Des Devel Ther 9: 5671-5686, 2015.
19. Liu H, Zang C, Fenner MH, Possinger $\mathrm{K}$ and Elstner $\mathrm{E}$ PPARgamma ligands and ATRA inhibit the invasion of human breast cancer cells in vitro. Breast Cancer Res Treat 79: 63-74, 2003.

20. Kim JS, Kang CG,Kim SH and Lee EO: Rhapontigenin suppresses cell migration and invasion by inhibiting the PI3K-dependent Racl signaling pathway in MDA-MB-231 human breast cancer cells. J Nat Prod 77: 1135-1139, 2014.

21. Kim J, Jeong H, Lee Y, Kim C, Kim H and Kim A: HRG- $\beta 1$-driven ErbB3 signaling induces epithelial-mesenchymal transition in breast cancer cells. BMC Cancer 13: 383, 2013.

22. Silveri L, Tilly G, Vilotte JL and Le Provost F: MicroRNA involvement in mammary gland development and breast cancer. Reprod Nutr Dev 46: 549-556, 2006.

23. Wark AW, Lee HJ and Corn RM: Multiplexed detection methods for profiling microRNA expression in biological samples. Angew Chem Int Ed Engl 47: 644-652, 2008.

24. Li J, Shen L, Xiao XG and Fang L: MicroRNAs in breast cancer and breast cancer stem cells and their potential for breast cancer therapy. Chin Med J 126: 2556-2563, 2013.

25. Han J, Lee Y, Yeom KH, Kim YK, Jin H and Kim VN: The Drosha-DGCR8 complex in primary microRNA processing. Genes Dev 18: 3016-3027, 2004.

26. Bertoli G, Cava C and Castiglioni I: MicroRNAs: New biomarkers for diagnosis, prognosis, therapy prediction and therapeutic tools for breast cancer. Theranostics 5: 1122-1143, 2015.

27. Zhang B, Pan X, Cobb GP and Anderson TA: microRNAs as oncogenes and tumor suppressors. Dev Biol 302: 1-12, 2007.

28. Ahmad A, Ginnebaugh KR, Yin S, Bollig-Fischer A, Reddy KB and Sarkar FH: Functional role of miR-10b in tamoxifen resistance of ER-positive breast cancer cells through down-regulation of HDAC4. BMC Cancer 15: 540, 2015.

29. Negrini M and Calin GA: Breast cancer metastasis: A microRNA story. Breast Cancer Res 10: 203, 2008.

30. Baffa R, Fassan M, Volinia S, O'Hara B, Liu CG, Palazzo JP, Gardiman M, Rugge M, Gomella LG, Croce CM, et al: MicroRNA expression profiling of human metastatic cancers identifies cancer gene targets. J Pathol 219: 214-221, 2009.

31. Bourguignon LY, Wong G, Earle C, Krueger K and Spevak CC: Hyaluronan-CD44 interaction promotes c-Src-mediated twist signaling, microRNA-10b expression, and RhoA/RhoC up-regulation, leading to Rho-kinase-associated cytoskeleton activation and breast tumor cell invasion. J Biol Chem 285: 36721-36735, 2010.

32. Ma L: Role of miR-10b in breast cancer metastasis. Breast Cancer Res 12: 210, 2010.

33. Ibrahim SA, Yip GW, Stock C, Pan JW, Neubauer C, Poeter M, Pupjalis D, Koo CY, Kelsch R, Schüle R, et al: Targeting of syndecan-1 by microRNA miR-10b promotes breast cancer cell motility and invasiveness via a Rho-GTPase- and E-cadherindependent mechanism. Int J Cancer 131: E884-E896, 2012.

34. Yigit MV, Ghosh SK, Kumar M, Petkova V, Kavishwar A, Moore A and Medarova Z: Context-dependent differences in miR-10b breast oncogenesis can be targeted for the prevention and arrest of lymph node metastasis. Oncogene 32: 1530-1538, 2013.

35. Jin H, Yu Y, Chrisler WB, Xiong Y, Hu D and Lei C: Delivery of microRNA-10b with polylysine nanoparticles for inhibition of breast cancer cell wound healing. Breast Cancer 6: 9-19, 2012.

36. Jung J, Yeom C, Choi YS, Kim S, Lee E, Park MJ, Kang SW, Kim SB and Chang S: Simultaneous inhibition of multiple oncogenic miRNAs by a multi-potent microRNA sponge. Oncotarget 6: 20370-20387, 2015. 